Copyright $(\mathcal{C} 2018$ by the Kalmyk Scientific Center of the Russian Academy of Sciences

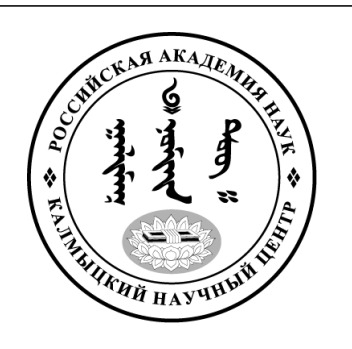

Published in the Russian Federation

Oriental Studies (Previous Name: Bulletin of the Kalmyk Institute for

Humanities of the Russian Academy of Sciences)

Has been issued as a journal since 2008

ISSN: 2619-0990; E-ISSN: 2619-1008

Vol. 38, Is. 4, pp. 156-164, 2018

DOI 10.22162/2619-0990-2018-38-4-156-164

Journal homepage: https://kigiran.elpub.ru

УДК 398

\title{
Фольклорные традиции пермских (гайнинских) башкир (по материалам экспедиций)
}

\author{
Айгуль Мужавировна Хакимьянова ${ }^{1}$ \\ ${ }^{1}$ кандидат филологических наук, научный сотрудник отдела фольклористики, Институт \\ истории, языка и литературы, Уфимский федеральный исследовательский центр РАН (450054, \\ Россия, г. Уфа, пр. Октября, 71). ORCID: 0000-0002-2786-3477. E-mail: aihakim@bk.ru \\ Гульнар Вилдановна Юлдыбаева \\ 2 кандидат филологических наук, старший научный сотрудник отдела фольклористики, \\ Институт истории, языка и литературы, Уфимский федеральный исследовательский центр РАН \\ (450054, Россия, г. Уфа, пр.Октября, 71). ORCID: 0000-0002-4973-2267. E-mail: nargul1976@, \\ list.ru
}

Аннотация. В статье дается история изучения и обзор полевой фольклористики башкиргайнинцев. Учеными Института истории, языка и литературы УФИЦ РАН организованы целенаправленные экспедиционные выезды по сбору образцов народного устно-поэтического творчества. На основе собранных материалов можно судить о состоянии традиционного фольклора башкир в современных условиях: в XXI в. устойчиво сохранились такие жанры, как баиты, мунажаты, песни, поверья, запреты, топонимические, исторические предания и легенды, продолжают активное бытование такие традиционные жанры, как такмаки, гадания. Ряд традиционных жанров народного творчества постепенно исчезает, прекратили бытование эпические жанры, постепенно угасает устная традиция сказки. Необходимо также отметить, что сегодняшняя полевая работа фольклористов сильно отличается от экспедиционных работ конца XX в. С каждым годом все меньше становится носителей традиционного фольклора, a оставшиеся обладают неполной информацией, что затрудняет работу фольклористов. Материалы научных экспедиций путем оцифровки и предварительной обработки введены в научно-исследовательский оборот.

Ключевые слова: экспедиция, фольклор, народное творчество, полевая фольклористика, башкирский народ, гайнинцы, жанры, современное состояние, устное бытование 
Пермские башкиры - этническая группа башкир, проживающих преимущественно в долине реки Тол (Тулвы), левого притока Камы, в пределах Бардымского района, где они известны как гайнинцы и бардымцы. Являются одним из автохтонных народов региона. Историческая этнография и этнические особенности пермских башкир довольно хорошо изучены. Еще в начале XVII в. Н. С. Попов рассматривал и описывал обряды и быт гайнинских башкир [Попов 1804].

Исторический этногенез и межродовые атрибуты гайнинцев подробно освещены в работах Р. Г. Кузеева [Кузеев 1992]. Исторические события, жизнь народа, особенности ведения хозяйства, сведения о переписи населения системно рассмотрены в работах башкирских ученых Н. М. Кулбахтина, А. 3. Асфандиярова и т. д. [Кулбахтин 2002; Асфандияров, Асфандиярова 1999]. Также исследованию пермских башкир с исторической, этнической и демографической точек зрения посвящены солидные труды Е. Н. Шумилова, Р. Ш. Валиуллина, А. В. Черных, Г. Н. Чагина и Р. М. Юсупова и т. д. [Шумилов 2002; Валиуллин 1998; Черных 1998; 2016; Чагин 2002; Юсупов 2002; 2006; 2012].

Основные этапы истории и проблемы идентичности гайнинских башкир затронуты в научном издании, посвященном истории башкирских родов. Объектом исследования 11 тома данной серии являются башкиры-гайнинцы, населяющие территории Бардымского и Пермского районов Пермского края, а также отдельные села Ачитского района Свердловской области, Альшеевского, Миякинского и Мечетлинского районов Республики Башкортостан. В работе имеется Приложение, в котором даны архивные документы, шежере (родословная), сведения ревизий 1859-1926 гг. [История башкирских 2015].

Как видно из вышесказанного, история и этническая особенность гайнинских башкир хорошо исследованы в научной литературе, однако духовный мир этноса невозможно раскрыть без изучения его устнопоэтического творчества. В связи с этим в $\mathrm{XX}$ в. начались целенаправленные экспедиционные исследования, командировочные выезды в данный регион - с целью сбора фактического материала.

Так, в 1963 г. состоялась комплексная экспедиция к гайнинским башкирам, ор- ганизованная Институтом истории, языка и литературы Башкирского филиала Академии наук СССР (ныне - Уфимский федеральный исследовательский центр Российской академии наук) под руководством А. Н. Киреева. Участниками экспедиции С. А. Галиным, Ф. А. Надршиной, А. Вахитовым и Н. Д. Шункаровым было обследовано 15 деревень с башкирским населением Бардымского, Чернушинского районов Пермской области РСФСР (Удик (Елпачиха), Кугия, Кудымъяр, Кайын, Бакса, Барда, Кызылъяр, Аржын, Аклыш, Конгук, Сарыш, Султанай, Башаптус, Танып).

В предисловии к архивным материалам руководитель экспедиции Н. Д. Шункаров писал: «Башкиры, живущие на этой территории называют себя „ғәйнә башкорттары“, т.е. „гайнинские башкиры“. Гайнинцы делятся на четыре типа: Тол-гайна, Мулгайна, Тор-гайна и Бисер-гайна. Кроме этих в долине реки Тол можно услышать названия Танып и Иректы. Среди родовых подразделений еще распространены ар, сирмеш, истяк» [НА УФИЦ РАН. Ф. 3. Оп. 2. Д. 225. Л. 7].

Ученый-филолог и фольклорист А. Н. Киреев записал несколько легенд и преданий о происхождении башкир-гайнинцев, родоначальниками которых являются братья Айна (Әйнә) и Гайна (Ғәйнә), предстающие в виде культурных героев, демиургов: «В районе реки Тол (Тулва) появляются два брата Гайна (Ғәйнә) и Айна (Әйнә). В одних вариантах они спускаются с неба, а в других - едут из снежных стран. Едут эти братья на священном олене. И вдруг олень останавливается, топает ногой. Братья обнаруживают на этом месте огонь, спрятанный злой хозяйкой Тулава („тул“ - огонь, „ава“ - хозяйка). Братья вступают в борьбу с хозяйкой огня. Один из них погибает. А другой, по имени Гайна, победив хозяйку огня, высвобождает огонь из-под земли и, вложив его в мешок, сделанный из оленьей кожи, переправляется на южный берег реки Тол, где основывает свой яйляу, свои иль, и становится зачинателем рода Гайна (Ғәйнә)» [Башкорт легендалары 1969: 55-56].

В некоторых вариантах братья добывают из-под земли Солнце [Башкорт легендалары 1969: 55]. В мировом фольклоре этиологический мотив возникновения Солнца считается древнейшим. Есть варианты, где братья находят воду, спрятанную в подзе- 
мелье, и освобождают ее. Отсюда возникает река Тол $($ Тулва), и сами они получают название тулвинцев или тулбуйцев [Башкорт легендалары 1969: 55-56].

Интересно отметить, что этноним Тулбуй (Тулва) указывает на прямую связь данного башкирского племени с древними финно-угорскими племенами. В языке некоторых народов финно-угорской группы, в частности в марийском и мордовском языках, слово Тулва означает 'хозяйка огня' (тул 'огонь', ава 'хозяйка'), а в карельском языке - 'хозяйка воды' [Башкорт легендалары 1969: 164].

В материалах экспедиции богато представлены все известные жанры башкирского фольклора. Ярко выраженной особенностью устно-поэтического творчества Пермского края того времени является устойчивость эпических традиций. Учеными-полевиками зафиксировано 16 сказок, большинство сюжетов которых относятся к бытовым («Зирәк егет», «Көтөүсе батша», «Хан менән ярлы кызы», «Үгәй инә» и т. д.). Архивные материалы показывают, что у гайнинских башкир доминирует жанр песни. Наряду с широко известными протяжными песнями распространены короткие по форме и быстрые по темпу исполнения песни без названий. Такие песни в народе называются төрлө йырз̧ар ('разные песни'), так как их можно исполнить под любую мелодию.

Фольклористами XX в. также зафиксировано множество топонимических и исторических преданий. Изучая архивные материалы, можно обнаружить обилие текстов жанра сеңләу (свадебных причитаний). Особенностью фольклорных материалов является развитие «письменной поэзии» (дәфтәр поэзияhыl), благодаря которой в памяти населения хранятся уникальные образцы песен, стихов-посвящений, баитов и мунажатов.

Богатый фольклор пермских башкир, имеющий большую научно-познавательную ценность, в значительной части введен в научный оборот. Собранные материалы были опубликованы в восемнадцатитомном своде башкирского устного народного творчества, которые нашли отражение также в путевых заметках и публицистических статьях Кирея Мэргена, Салавата Галина, Фанузы Надршиной и др.

В 1973 г. в восьми населенных пунктах Пермской области (Бичурино, Елпачиха, Ишимово, Краснояр, Нижняя Искильда,
Ольховка, Султанай, Танып) работала диалектологическая экспедиция Института истории, языка и литературы БФ АН СССР. Материалы экспедиции вошли в третий том издания «Словарь башкирских говоров. Западный диалект» (1983), а в 2002 г. - в «Диалектологический словарь башкирского языка», в которые были включены отдельные слова из лексики гайнинского говора. Лексика говора также была отражена во втором томе «Словаря башкирских говоров», которая была издана в 1970 г.

По мнению диалектологов, язык пермских башкир является гайнинским говором северо-западного (западного) диалекта башкирского языка [Миржанова 2006: 210288]. Бытовой говор гайнинцев и пермских татар Д. Б. Рамазанова относит к одному из говоров среднего диалекта татарского языка, а точнее - к бардымского подговору. Она отмечает близость бардымского подговора с башкирским языком больше по лексике и ничего общего - по фонетике [Paмазанова 1996: 36-38]. Однако, по мнению башкирского исследователя Р. М. Юсупова, в «татаризации» языка гайнинских башкир большую роль сыграли обучение в общеобразовательных школах, издание СМИ и периодики, а также радиовещание на татарском языке [Башкиры-гайнинцы 2012: 13].

В 2006 г. Институтом истории, языка и литературы УНЦ РАН была организована комплексная экспедиция в Пермский край, в котором участвовали языковеды, этнографы и фольклористы. Наряду с собиранием и изучением народно-поэтического творчества, языкового материала башкирского народа этого края, ученые поставили перед собой задачу антропологических и краниологических исследований.

Во время этой поездки были получены материалы по краниологии, дерматоглифике, производилось антропологическое фотографирование в фас и профиль исследуемого населения. Что касается образцов устно-поэтического творчества, по словам фольклориста Р. А. Султангареевой, зафиксированы образцы религиозного фольклора, исторические материалы, касающиеся этногенеза башкирского народа [Ғәйнә башкорттары 2012: 10-16].

К сожалению, во время полевой работы не обнаружены крупные эпические произведения, народные песни озон көй ('протяжные песни'). Собранный материал введен в научный оборот, в 2008 г. увидел свет круп- 
ный коллективный труд «Башкиры-гайнинцы Пермского края. История, этнография, антропология, этногеномика» [Башкирыгайнинцы 2008], а в 2012 г. опубликован фольклорный сборник «Ғәйнә башкорттары фольклоры» [Ғәйнә башкорттары фольклоры 2012].

В 2013 г. в рамках проекта «Экспедиционный выезд в Пермский край» при поддержке РГНФ состоялась экспедиция фольклористов ИИЯЛ УНЦ РАН в Пермский край РФ. Ее задача - сбор башкирского традиционного устного народного творчества по всем жанрам, изучение современного его состояния. Члены академической экспедиции (Юлдыбаева Г. В., Хакимьянова А. М., Хусаинова Г. Р.) работали в трех районах края: Пермском, Бардымском и Уинском. Исследовано восемь башкирских деревень: Сосновка (Толбаш), Танып, Константиновка (Күстәнтәй), Сараш, Султанай (Солтанай), Сюзянь (Сөжән), Бурузли (Бөрөзлө), Башкултай (Башкултай).

Временной разрыв между первой и данной экспедицией - более 50 лет. За это время произошло много изменений как в социально-экономической, так и культурной, и научной жизни общества. Экспедиция оказалась плодотворной, участники записали значительное количество произведений различных жанров башкирского фольклора. Среди них встречаются как впервые обнаруженные, так и варианты произведений, ранее записанных в других местах. К работе фольклористов были привлечены более 50 информантов, основной контингент которых составили люди в возрасте от 35 лет до 90 лет.

Анализ собранного материала показывает значительное обеднение и сокращение жанрового состава фольклора. Ряд традиционных форм фольклора разрушается и постепенно уходит в историю: почти прекратили существование эпические жанры, постепенно угасает устная традиция бытования сказки. Эпические тексты, сказки, записаны из уст информантов во фрагментарном виде, в форме пересказа.

Необходимо заметить, что в регионе зафиксированы яркие образцы протяжных («Шахта көйө», «Сарман буйз̧ары», «Сыбай кашка», «Маһисәрүәр»), коротких, колыбельных песен (сәли йырзары), частушек (такмаков).

Для репертуара гайнинских башкир характерны такие поэтические жанры, как баиты и мунажаты. В исследуемом нами регионе обнаружены социально-бытовые и исторические баиты с драматической сюжетной основой («Мин китмәнем баз̧арға» («Я иду на базар»), «Шәмсекамал бәйете» («Баит Шамсикамал»), «Кыз̧ һатыу бәйете» («Баит о продаже девушки»), «Ғәлимә кыз тураһында» («О девушке Галиме»), «Йәш ялсы» («Молодой батрак»), «Әсмә бәйете» («Баит Асмы»), «һалдаттар бәйете» («Баит солдатов»), «һуғыш бәйете» («Баит о войне»), «Акмулла бәйете» («Баит Акмуллы»), «Акһак Тимер бәйете» («Баит Аксак Тимеpa»).

Тематика бытовых баитов охватывает многие стороны повседневной жизни и быта, но большинство посвящено несчастным случаям, гибели того или иного человека на дороге, «горячих точках» и т. д. Чаще всего слагателями и исполнителями таких баитов являются близкие родственники. Также записаны 10 текстов баита «СакСук» (4 полных варианта), в основе которого положен мифологический мотив о судьбе двух малолетних детей, проклятых матерью за непослушание. После чего дети разлетелись в разные стороны, превратившись в птиц Сак и Сук. Они могут встретиться только ночью. Однако перед каждой встречей наступает рассвет. Поэтому они вынуждены жить в одиночестве. Этот баит часто встречается в фольклоре татар и чувашей.

Широко распространены и активно бытуют мунажаты (религиозные песнопения), например: «Муса», «Йома» («Пятница»), «Салауат», «Йә, Хәбиби», «Мәрхәбә, хуш килдең, Мәрхәбә», «Йә илаһи иллалла», «Бала менән ана» («Мать и дитя»). Материалы фольклорных экспедиций свидетельствуют о возрождении этого уникального музыкального лиро-эпического жанра в современности и существовании его как в письменной, так и устной формах.

Среди материалов отмечены также истории сел и деревень (Танып, Брюзли, Султанай), топонимические легенды и предания («Семь святых» («Ете ғәзиз»), «Девушка Зухра» («Зөһрә кыз̧»). Повсеместно распространена легенда «Семь святых». По рассказам информантов, семеро святых, дорогих великанов охраняли нашу землю. Они жили на горе, если грозила какая-то опасность, они сигналили друг другу при помощи костров. У них есть имена: в Султанае - Султангазиз, в Тулбаше - Саитсалим, в Ииктау - Салтанахмет, в Ермеево - 
Султангали, в Красном яре - Хасаншаик, в Бузатау - Миниярмагасум, в Уралтау Муратхажи. На горе Этмеш похоронен один из них. Один похоронен в Сарашево, другой - в Аржаново. Все они похоронены в Бардымском районе [Полевые материалы 2013: 1]. Каждый день недели поочередно каждому из них читают молитвы. Если народ, не забывая своих святых, молится за них, то на земле будет мир и покой.

Интересные сведения зафиксированы о хозяевах различных объектов. По поверьям пермских башкир, кроме хозяина дома, двора, бани, существуют: хозяин земли - Жиржаз бабай, хозяин лошади - Жирембикә, скота - Занки бабай, овец - Сулпан әби, большой воды - Хыльlуян, малой воды Хусни Хакима, железа - Даут пророк, гусей - Гайса пророк, лошадей - Ахмет Ясави, пруда и моста - Палуан пророк, березы - Лут пророк, елки - Чыма пророк, глаз - Тутыля әби, дороги - Багауитдин, крови - хозяин Гилфан, силы - Гаил пророк, здоровья - Ахмай Жами и т. д. [Полевые материалы 2013: 2]. Информанты утверждают, что, читая молитвы, необходимо посвящать их и перечисленным выше хозяевам.

У гайнинцев бытуют локальные особенности свадебного обряда. Так, например, родителей невесты (жениха) в дом заносят на руках, оказывая особый почет и уважение. Также жениха подбрасывают на постель, заранее приготовленный тестем. По условиям обряда, сколько слоев постели, столько дней будет длиться свадьба. Родители жениха в дом невесты приносят гульбадию (баш. гөлбәз̧иә) - свадебный пирог с многослойной начинкой. Каждый слой должен состоять из различных ягод: малины, смородины, изюма и т. д. Сколько слоев в пироге - столько ночей должны переночевать сватья в этом доме. Пирог должен делить уважаемый человек рода, которого после одаривают полотенцем или рубахой. Пирог делится на четыре части: одну часть сваты обратно везут домой - для угощения соседей, вторая часть остается у стороны невесты, а две остальные части раздаются гостям свадьбы. На свадьбе все должны попробовать этот пирог. И это главное блюдо свадьбы приглашенные гости должны обязательно выкупить.

На второй день после свадьбы снохи невесты готовят обрядовую баню. При отсутствии честности невесты, жених в бане оставлял продырявленную монету. Осуждать за это действо его никто не имел права. После свадьбы родители жениха приглашают в гости новоиспеченных сватов. Этот обычай называют hыныкка сакырыу (досл. 'приглашение к отломленному куску') [Полевые материалы 2013: 3].

В башкирском фольклоре широко распространен обряд «выкупа ребенка», который проводили люди, у которых умирали дети. Обычно во время выкупа ребенка «продавали» через оконный проем, но в данном регионе обряд проводится в виде имитации родов. Для его проведения обращаются к многодетным женщинам. Например, как рассказывает информант: «Эта женщина приготовила стол, купила моему ребенку новую рубаху и сама одела длинное платье с широким подолом и застежками спереди. Когда мы пришли к ней домой, она взяла ребенка в руки, засунула его через грудь в платье и высунула из-под подола, как бы показывая что она сама родила этого ребенка. Затем надела на него новую рубаху и сказала: „Теперь ты мой ребенок!“». После чаепития мы поблагодарили женщину, подарили ей платье и с ребенком пошли домой. Сейчас этому ребенку тридцать лет» [Полевые материалы 2013: 4].

Отличительной особенностью фольклора гайнинцев является распространение способов гаданий молодых девушек на замужество. Например, 6 апреля они называют тын тыңлаван кис (букв. 'вечер прослушки дыхания'). В этот вечер молодые украдкой подслушивают возле окон людей (соседей, односельчан), и по услышанному предсказывают свое будущее.

Еще один интересный вид предсказания, когда девушки гадают посредством счета изгороди. При счете называют бишек ('колыбель'), сымылдықк ('занавесь'), капсык ('мешок'). Если останавливаешься на бишек, то будешь жить богато, на сымылдыьк - хорошо, на капсык - бедно [Полевые материалы 2013: 5].

Также гадают, обнимая изгородь. Считают колышки, которые можешь объять, при счете говорят: егет, бабай, егет, бабай. Если счет заканчивается на егет, выйдешь замуж за молодого, если на бабай за старого [Полевые материалы 2013: 6]. В этот вечер девушки еще гадали так: через дымоход в бане высовывали руку. Все жители деревни знали о гадании. Если за руку возьмется человек с твердой рукой, то вый- 
дешь замуж за старого, если же наоборот за молодого. Также гадали выбрасыванием киштек (суконная обувь) через ворота. Куда смотрит носок обуви, в ту сторону выйдешь замуж [Полевые материалы 2013: 5].

2 августа пермские башкиры называют иллә көн - день сбора лекарственных трав. Травы, собранные в этот день, приносят большую пользу. Говорят, в этот день рождаются счастливые дети, в «рубашке» [Полевые материалы 2013: 5].

Богатый пласт пермского народного творчества также составляют малые жанры фольклора: заклички, приговоры, загадки, пословицы, поговорки.

Таким образом, в данной статье мы рассмотрели историю изучения и современное состояние башкирского фольклора Пермского края РФ. Обзор материала показывает, что, несмотря на угасание некоторых традиционных жанров (эпос, сказки, свадебные причитания), поныне бытуют обряды, песни, баиты, мунажаты, игры и паремические жанры. Собранный фольклористами-полевиками интересный материал показывает устойчивое сохранение башкирского народного творчества в этом регионе.

\section{ЛИТЕРАТУРА / REFERENCES}

Асфандияров, Асфандиярова 1999 Асфандияров А. 3., Асфандиярова К. М. История башкирских сел Пермской и Свердловской областей. Кн. 8. Уфа: Китап, 1999. С. 6-9 [Asfandiyarov A. Z., Asfandiyarova K. M. Istoriya bashkirskikh sel Permskoy $i$ Sverdlovskoy oblastey [History of Bashkir villages located in Perm and Sverdlovsk Oblasts]. Book 8. Ufa: Kitap, 1999. Pp. 6-9. (In Rus.)]

Башкиры-гайнинцы 2008 - Башкиры-гайнинцы Пермского края. История, этнография, антропология, этногеномика. Уфа: Гилем, 2008. 336 c. [Bashkiry-gaynintsy Permskogo kraya: istoriya, etnografiya, antropologiya, etnogenomika [The Gaina Bashkirs of Perm Krai: history, ethnography, anthropology, ethnogenomics]. Ufa: Gilem, 2008. 336 p. (In Rus.)]

Башкиры-гайнинцы 2012 - Башкиры-гайнинцы: история и современность. Уфа: Китап, 2012. 264 c. [Bashkiry-gaynintsy: istoriya $i$ sovremennost [The Gaina Bashkirs: history and contemporaneity]. Ufa: Kitap, 2012. 264 p. (In Rus.)]

Башкорт легендалары 1969 - Башкорт легендалары / Төз., ис̧кәрмә биреүселәр һәм ред. М. Х. Мингажетдинов, Кирей Мэргэн. Өфө, 1969. 186 с. [Bashqort legendalary [Bashkir legends]. M. Kh. Mingazhetdinov, Kirei Mergen (eds., etc.)]. Ufa: Ufa Publ., 1969. 186 p. (In Bash.)]

Валиуллин 1998 - Валиуллин Р. Ш. Очерки по истории родного края. Барда: [б. и.], 1998. 158 c. [Valiullin R. Sh. Ocherki po istorii rodnogo kraya [Essays on the history of the ancestral lands]. Barda, 1998. 158 p. (In Rus.)]

Ғәйнә башкорттары 2012 - Ғәйнә башкорттары фольклоры (перевод на рус. здесь) / авт.-төз. Р. Ә. Солтангәрәйева, төз. Ф. Ф. Ғайсина. Баш һүз авт. Р. Ә. Солтангәрәйева. Өфө: Ғилем, 2012. 172 б. ['̈әуnə bashkorttary fol'klory [Folklore of the Gaina Bashkirs]. R. Sultangareeva (comp.) et al. Ufa: Ǵilem, 2012. 172 p. (In Bash.)]

История башкирских 2015 - История башкирских родов. Гайна. Том 11 / С. И. Хамидуллин, Ю. М. Юсупов, Р. Р. Асылгужин, Р. Р. Шайхеев, И. Р. Саитбатталов, В. Г. Волков, А. А. Каримов, А. М. Зайнуллин, А. Р. Махмудов, Р. М. Рыскулов, А. Р. Асылгужин, А. Я. Гумерова, Г. Ю. Галеева, Г. Д. Султанова. Уфа: Уфимский полиграфкомбинат, 2015. 696 с. [Istoriya bashkirskikh rodov. Gaina [History of Bashkir clans: Gaina]. Vol. 11. S. I. Khamidullin, Yu. M. Yusupov, R. R. Asylguzhin et al. Ufa: Ufa Publ., 2015. 696 p. (In Rus.)]

Кузеев 1992 - Кузеев Р. Г. Народы Среднего Поволжья и Южного Урала. М.: Наука, 1992. 347 c. [Kuzeev R. G. Narody Srednego Povolzh'ya i Yuzhnogo Urala [Peoples of the Middle Volga Region and Southern Urals]. Moscow: Nauka, 1992. 347 p. (In Rus.)]

Кулбахтин 2002 - Кулбахтин Н. М. Территория расселения и численность гайнинских башкир в XVIII - первая половина XIX в. // Башкиры племени гайна. Уфа: Китап, 2002. C. 4-10. [Kulbakhtin N. M. The Gaina Bashkirs: inhabited areas and population size in the $18^{\text {th }}$ - early-to-mid $19^{\text {th }}$ cc. Bashkiry plemeni gayna [Bashkirs of the Gaina tribe]. Ufa: Kitap, 2002. Pp. 4-10. (In Rus.)]

Миржанова 2006 - Миржанова С. Ф. Северозападный диалект башкирского языка. Уфа: Китап, 2006. 295 с. [Mirzhanova S. F. Severozapadnyy dialekt bashkirskogo yazyka [The northwestern dialect of the Bashkir language]. Ufa: Kitap, 2006. 295 p. (In Rus.)]

НА УФИЦ РАН - Научный архив Уфимского федерального исследовательского центра РАН. Ф. 3. Оп. 2. Д. 225. Л. 7. [Nauchnyy arkhiv Ufimskogo federal'nogo issledovatel'skogo tsentra Rossiyskoy akademii nauk [Scientific 
Archive of Ufa Federal Research Center of the RAS]. F. 3. Op. 2. D. 225. P. 7.]

Полевые материалы 2013 - Полевые материалы, собранные фольклористами в 2013 г. Фольклорный фонд ИИЯЛ УФИЦ РАН. [Polevyye materialy, sobrannyye fol'kloristami $v 2013 \mathrm{~g}$. [Field data collected by folklorists in 2013]. Fol'klornyy fond IIYaL UFITs RAN [Folklore Fund at the Institute of History, Language and Literature, Ufa Research Center of the RAS.]

Попов 1804 - Попов Н. С. Хозяйственное описание Пермской губернии. Пермь: Пермское губернское правление. 1804. 399 с. [Popov N. S. Khozyaystvennoye opisaniye Permskoy gubernii [An economic description of Perm Governorate]. Perm, 1804. 399 p. (In Rus.)]

Рамазанова 1996 - Рамазанова Д. Б. К истории формирования говора пермских татар. Казань: ИЯЛИ, 1996. 239 с. [Ramazanova D. B. K istorii formirovaniya govora permskikh tatar [Perm Tatars: history of the dialect formation revisited]. Kazan: IYaLI, 1996. 239 p. (In Rus.)]

Чагин 2002 - Чагин Г. И. Пермские башкиры: история и современная демографическая ситуация в области // Демография башкирского народа: прошлое и настоящее. Уфа: Изд-во Башкирск. гос. ун-та, 2002. C. 55-62. [Chagin G. I. Perm Bashkirs: history and current demographic situation in the region. Demografiya bashkirskogo naroda: proshloye $i$ nastoyashcheye [Demography of the Bashkir people: past and present]. Ufa, 2002. Pp. 55-62. (In Rus.)]

Черных 1998 - Черных A. B. Этнический состав населения и особенности расселения в южном Прикамье в XVI - первой четверти XX в. // Этнические проблемы регионов России. Пермская область. М.: Старый сад, 1998. C. 39-113. [Chernykh A. V. Ethnic population structure and peculiarities of allocation in Southern Prikamye: $16^{\text {th }}-$ early $20^{\text {th }} \mathrm{cc}$. Etnicheskiye problemy regionov Rossii. Permskaya oblast' [Ethnic problems of Russia's regions. Perm Oblast]. Moscow: Staryj sad, 1998. Pp. 39-113. (In Rus.)]

Черных 2016 - Черных A. B. Башкиры Перми: история и культура. СПб: Маматов, 2016. 64 c. [Chernykh A. V. Bashkiry Permi: istoriya $i$ kul'tura [Bashkirs of Perm: history and culture]. St. Petersburg: Mamatov, 2016. 64 p. (In Rus.)]

Шумилов 2002 - Шумилов Е. Н. Гайнинские (бардымские) башкиры Пермской области
// Демография башкирского народа: прошлое и настоящее. Мат-лы межрегион. научн.-практ. конф., посв. II Всемирному курултаю башкир. Уфа: изд-во Башкирского ун-та, 2002. С. 88-104. [Shumilov E. N. The Gaina Bashkirs of Perm Oblast. Demografiya bashkirskogo naroda: proshloye $i$ nastoyashcheye. Conf. proc. Ufa: Bashkir State Univ., 2002. Pp. 88-104. (In Rus.)]

Юсупов $2002-$ Юсупов Р. М. Антропологический состав башкир и его формирование // Башкиры. Этническая история и традиционная культура / под общ. ред. Р. М. Юсупова. Уфа: Башкирская энциклопедия, 2002. С. 11-20. [Yusupov R. M. The anthropological structure of Bashkirs and its formation. Bashkiry. Etnicheskaya istoriya i traditsionnaya kul'tura [The Bashkirs. Ethnic history and traditional culture]. R. Yusupov (ed.). Ufa: Bashkirskaya Entsiklopediya, 2002. Pp. 11-20. (In Rus.)]

Юсупов 2006 - Юсупов P. М. Этнология башкир на рубеже тысячелетий // Проблемы этногенеза и этнической истории башкирского народа. Уфа, 2006. С. 95-101. [Yusupov R. M. Bashkir ethnology at the turn of the millennia. Problemy etnogeneza $i$ etnicheskoy istorii bashkirskogo naroda [Problems of ethnogenesis and ethnic history of the Bashkir people]. Ufa, 2006. Pp. 95-101. (In Rus.)]

Юсупов 2012 - Юсупов Р. М. История расселения, демография, этноним // Башкирыгайнинцы: история и современность. Уфа: Китап, 2012. С. 7-19. [Yusupov R. M. History of dissemination, demography, ethnonym. Bashkiry-gaynintsy: istoriya i sovremennost'. Ufa: Kitap, 2012. Pp. 7-19. (In Rus.)]

\section{ПОЛЕВОЙ МАТЕРИАЛ АВТОРОВ / AUTHORS' FIELD DATA}

Записано Хакимьяновой А. М. от Масагутовой Гульжихан Казыхановны, 1942 г. р., в дер. Султанай Бардымского района Пермского края РФ. [Recorded by A. M. Khakimyanova from Gulzhikhan K. Masagutova, born 1942, Sultanay village, Bardymsky District, Perm Krai of Russia.]

Записано Юлдыбаевой Г. В. от Уртабаева Шарифьяна Муллаяновича, 1949 г. р., дер. Брюзли, Габзалиловой Алимы Гатиевны, 1949 г. р., в дер. Брюзли Бардымского района Пермского края РФ. [Recorded by G. V. Yuldybaeva from Sharifyan M. Urtabaev, born 1949, Bryuzli village; from Alima G. Gabzalilova, born 1949, Bryuzli village, Bardymsky District, Perm Krai of Russia.] 
Записано Юлдыбаевой Г. В. от Гузаировой Фании Нажмухаметовны, 1928 г. р., дер. Константиновка Бардымского района Пермского края РФ. [Recorded by G. V. Yuldybaeva from Faniya N. Guzairova, born 1928, Konstantinovka village, Bardymsky District, Perm Krai of Russia.]

Записано Хакимьяновой А. М. от Халитовой Расимы Мусовны, 1948 г. р, в дер. Сюзянь Бардымского района Пермского края РФ. [Recorded by A. M. Khakimyanova from Rasima M. Khalitova, born 1948, Syuzian village, Bardymsky District, Perm Krai of
Russia.]

Записано Юлдыбаевой Г. В. от Габдукаевой Каусарии Нажмулловны, 1961 г. р., в дер. Сараш Бардымского района Пермского края PФ. [Recorded by G. V. Yuldybaeva from Kausariya N. Gabdukaeva, born 1961, Sarash village, Bardymsky District, Perm Krai of Russia.] Записано Юлдыбаевой Г. В. от Азнагуловой Гадили Ахметхановны, 1930 г. р., в дер. Танып Бардымского района Пермского края PФ. [Recorded by G. V. Yuldybaeva from Gadil A. Aznagulova, born 1930, Tanyp village, Bardymsky District, Perm Krai of Russia.]

\title{
Folklore Traditions of Perm (Gaina) Bashkirs (a Case Study of Expeditionary Materials)
}

\author{
Aigul M. Khakimyanoval
}

${ }^{1}$ Ph.D. in Philology (Cand. of Philological Sc.), Research Associate, Folklore Research Department, Institute of History, Language and Literature, Ufa Federal Research Center of the RAS (71, October Av., Ufa, 450054, Russian Federation). ORCID: 0000-0002-2786-3477. E-mail: aihakim@bk.ru

\section{Gulnar V. Yuldybaeva ${ }^{2}$}

${ }^{2}$ Ph.D. in Philology (Cand. of Philological Sc.), Senior Research Associate, Folklore Research Department, Institute of History, Language and Literature, Ufa Federal Research Center of the RAS (450054, October Av., 71, Ufa, Russian Federation). ORCID: 0000-0002-4973-2267. E-mail: nargul1976@list.ru

Abstract. The Gaina Bashkirs are an ethnic group of the Bashkir people basically inhabiting the Tol (Tulva) River Valley, a left tributary of the Kama, within the boundaries of Bardymsky District where they constitute one of the autochthonous populations of the region. The region is vivid and multifaceted; a number of monographs and collections of scientific works have been published. Several expeditions and surveys have been organized to collect somewhat factual materials.

In the $21^{\text {st }}$ century, two academic expeditions have been conducted by researchers of the Institute of History, Language and Literature of the Ufa Federal Research Center of the RAS. In 2006, the goals of a complex expedition - which involved linguists, ethnographers and folklorists - included not only collecting activities, studies of folklore poetic patterns and linguistic materials, but also anthropological and craniological research. In 2013, folklore specialists of the Institute organized another expedition to Perm Krai.

Analysis of the collected materials shows a significant depletion and reduction in the genre structure of folklore patterns. A number of traditional forms of folklore - such as epic genres and oral fairy-tale traditions - are becoming extinct gradually. So, epic texts and fairy tales were recorded from informants in a fragmentary form, in the form of retelling.

The first folklore research expedition arrived in the Gaina in 1963. Thus, the time gap between the first expedition and the last one is more than 50 years. During the period, the population (and the country in general) had experienced some essential transformations, both in terms of socium, economy, culture, and science. Still, the expedition proved fruitful enough, the participants recorded quite number of multi-genre works of Bashkir folklore. The latter included both some newly 
discovered patterns and new versions of the already recorded oral texts. The folklore collecting activities involved over 50 informants, the bulk of the group being individuals aged 35 to 90 .

As a result, bright samples of lingering and short lullabies, takmaks were recorded. For the repertory of Gaina Bashkirs is characterized by the abundance of such poetic genres as baits and munazhats. In the region, a number of social and historical baits with dramatic storylines have been discovered. Widespread are munazhats (religious hymns). For example, materials of folklore expeditions attest to the current revival of this unique musical lyric-epic genre, and its existence both in written and oral forms. The materials also include stories about villages, toponymic legends. Interesting information about spiritual hosts has been recorded. The Gaininians have their local features of wedding rites. A distinctive feature of Gainin folklore is the spread of numerous marriage divinations for young women.

A rich layer of Perm folk arts is also composed of small folklore genres, namely: zaklichki, verdicts, riddles, proverbs, sayings.

Consequently, despite the current extinction (decline) of some traditional genres (epic patterns, fairy tales, wedding laments), folk rites, songs, baits, munazhats, traditional games and paremic genres still do exist. The vivid field materials collected by folklorists show the steady preservation of Bashkir folk arts in the region.

Keywords: folklore field study, Bashkir people, genres, current status, oral existence 